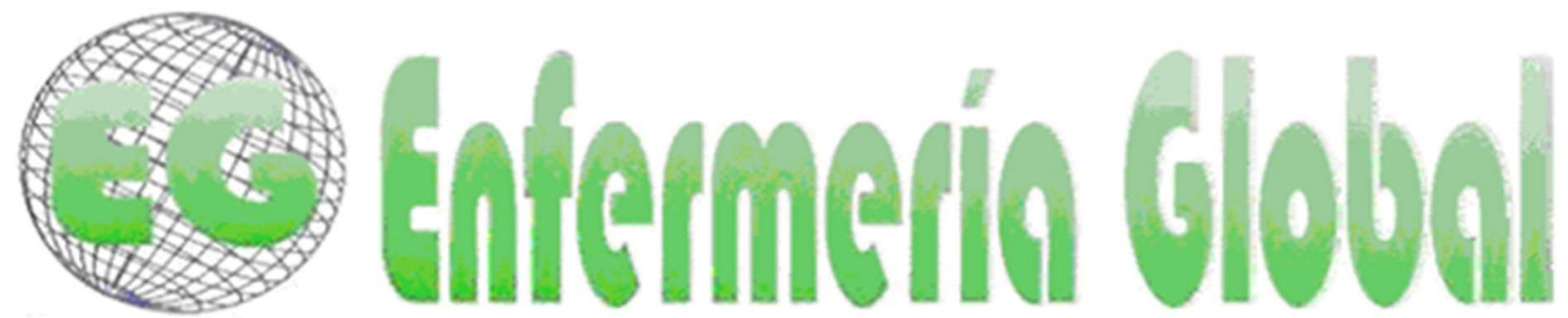

\title{
ORIGINALES
}

\section{EI VIH como vía de materialización de la Violencia de Género e Intragénero}

HIV as a means of materializing Gender Violence and violence in same-sex couples

\author{
Luis Manuel Rodríguez Otero ${ }^{1}$ \\ María Gabriela Lara Rodríguez ${ }^{2}$
}

${ }^{1}$ Doctor en Trabajo Social. Personal Docente Investigador/a de Facultad de Trabajo Social de Culiacán. Universidad Autónoma de Sinaloa. México. luismaotero@yahoo.es

${ }^{2}$ Trabajadora Social del Hospital General de Zona con Medicina Familiar $n^{\circ} 6$ del Instituto Mexicano del Seguro Social (IMSS) de Nuevo León. México.

\section{https://doi.org/10.6018/eglobal.435891}

Recibido: $7 / 07 / 2020$

Aceptado: 5/10/2020

\section{RESUMEN:}

Objetivo: El objetivo general de esta investigación consiste en identificar la prevalencia y características de la violencia en pareja (perpetrador/a y receptor/a) en pacientes seropositivos adscritos al Instituto Mexicano del Seguro Social (IMSS) de Nuevo León (México).

Método: Se ha planteado una investigación cuantitativa, a través de un diseño descriptivo y transversal, utilizando como instrumento principal la escala Likert de violencia en la relación de pareja de Cienfuegos y la escala Likert sobre el uso del VIH como vía de materialización de la violencia. Se aplicaron 265 cuestionarios autoadministrados y se obtuvo una muestra de 198 pacientes

Resultados: Existe una prevalencia de la violencia en pareja como receptor/a del $40.40 \%$ y como perpetrador/a del $40.90 \%$, siendo en ambas formas la violencia psicológica la más frecuente. La prevalencia del uso del VIH como vía de materialización de la violencia en pareja como receptor/a es del $4.54 \%$ y como perpetrador/a del $2.52 \%$. Existe una mayor proporción de víctimas y agresores mujeres, no heterosexuales y de parejas en la que ambos miembros son seropositivos; así como en pacientes con mayor nivel de apego seguro y satisfacción con la vida.

Conclusiones: Al igual que en la VG, se constata la existencia de violencia en relaciones formas por personas del mismo sexo en la que alguno de sus miembros es seropositivo/a. Asimismo, se corrobora que el VIH se utiliza como medio para ejercer la violencia en pareja.

Palabras claves: violencia en pareja; violencia intragénero; $\mathrm{VIH}$.

\section{ABSTRACT:}

Objective: The general objective of this research is to identify the prevalence and characteristics of partner violence (perpetrator and recipient) in HIV positive patients enrolled in the Mexican Institute of Social Security (IMSS, in Spanish) in the state of Nuevo Leon, Mexico.

Methodology: A quantitative research was proposed, through a descriptive and transversal design, using as main instrument the Likert scale of violence in partner relationships of Cienfuegos and the Likert scale on the use of HIV as a means to materialize violence. We applied 265 self-administered questionnaires and obtained a statistic sample of 198 patients 
Results: There is a prevalence of partner violence of $40.40 \%$ as a receiver and of $40.90 \%$ as a perpetrator, psychological violence is the most frequent form in both cases. The prevalence of the use of HIV as a means of materializing partner violence as a recipient is of $4.54 \%$ and of $2.52 \%$ as a perpetrator. There is a higher proportion of non-heterosexual female victims and aggressors, and of couples in which both members are HIV positive; as well as in patients with a higher level of secure attachment and satisfaction with life.

Conclusions: As in GBV (gender-based violence), there is evidence of the existence of violence in same-sex relationships in which one of the members is HIV positive. Likewise, it is possible to corroborate that HIV is used as a means to exercise partner violence.

Key words: partner violence; intra-gender violence; HIV

\section{INTRODUCCIÓN}

La literatura científica referente a la violencia de género (VG), evidencia que las mujeres portadoras del virus de inmunodeficiencia humana $(\mathrm{VIH})$ registran una elevada incidencia, siendo la mitad de las mujeres víctimas por parte de sus parejas (1); incluso diferentes estudios sitúan la incidencia superior a las parejas en la que ninguno de sus miembros es seropositivo/a ${ }^{(2)}$.

El estigma socialmente adscrito al virus coadyuva al sometimiento que las culturas patriarcales reproducen en torno a las mujeres ${ }^{(3,4)}$; lo cual se produce a través de procesos en los que la falta de reconocimiento se materializa mediante diferentes formas de menosprecio. En este sentido, en la esfera afectiva el reconocimiento (amor), el principio de atención de la necesidad se alcanza mediante la autoconfianza y hace uso del maltrato como vía del desprecio ${ }^{(5)}$.

Alonso, Cerezo, Pagés, Ramos y Torricelli señalan que respecto al VIH y la VG existen determinantes social que ejercen como factores determinantes, entre los cuales señalan: (1) la percepción social de la violencia, la inseguridad y la impunidad, (2) el acceso limitado a la educación y el trabajo, (3) el acceso restringido a la atención integral y diferenciada en los servicios de salud, (4) las conductas sociales machistas y el patriarcado, (5) la discriminación de las personas por su orientación sexual y (6) la estigmatización y la discriminación hacia mujeres con $\mathrm{VIH}{ }^{(6)}$. Asimismo, respecto a formas específicas en las que se utiliza el VIH como vía de materialización de la VG (además de la violencia física, psicológica, económica y sexual), diferentes autores describen acciones como: (1) impedir el acceso al tratamiento antirretroviral, (2) prohibir el acceso a las consultas, (3) desaconsejar la toma de medicación/tratamiento y (4) destruir la medicación antirretroviral (2,7). Este conjunto de factores representa los desencadenantes tanto de repercusiones sociales, como de consecuencias para la salud física y psicosocial de las mujeres; incluida la disminución de linfocitos CD4+ ${ }^{(8)}$.

Una de las variables utilizadas para analizar las relaciones de pareja es el apego, el cual refiere a un modelo de autoesquema que regula las relaciones hacia con los demás, con base en patrones de interacción social relacionados con lazos afectivos ${ }^{(9)}$; identificando cuatro principales esquemas (10): (1) el apego seguro (alta valoración personal, siente comodidad con la intimidad y la autonomía), (2) el apego preocupado (baja valoración personal y una evaluación positiva de los otros), (3) el apego temeroso (poca valoración personal, teme la intimidad y es socialmente evitante) y (4) el apego evitante (alta valoración personal, rechaza la intimidad y la dependencia). 
Tomando en consideración el contexto latinoamericano el estudio sobre la VG y el VIH es escaso; así en Colombia el estudio cuantitativo de Arévalo-Mora (8) identificó que de 223 mujeres seropositivas, el 33,6\% presentaron violencia de pareja. También otro realizado por la misma autora, a través de una metodología cualitativa, advierte que este tipo de situaciones tiene como consecuencia en las mujeres una baja autoestima, el daño en la autoimagen, elevadas tasas de depresión y sentimientos de culpabilización (11). Por otro lado, en Brasil un estudio señala que las víctimas presentan dificultad para reconocer los actos de violencia sexual (12), mientras que en otro estudio se aprecia que la vivencia de situaciones de VG influye en la adherencia al tratamiento (13); asimismo en un estudio elaborado en São Paulo con una muestra de 2.780 mujeres, señala que el $59.8 \%$ sufrió VG ${ }^{(14)}$, mientras que otro estudio señala que en una muestra de 57 mujeres de color brasileñas portadoras del VIH el $28 \%$ sufrió VG (15). En Argentina un estudio cualitativo analiza historias de vida de mujeres con VIH víctimas de VG y las políticas públicas al respecto (16); otro estudio cualitativo señala que la opresión racial y de género representan factores favorecedores de la VG (17). Respecto a Chile un estudio con una muestra de 100 mujeres seropositivas identificó que el $77 \%$ sufrió VG, siendo la violencia psicológica la más frecuente ${ }^{(18)}$. Finalmente, en México en una investigación con población indígena se constata la existencia de este tipo de violencia e indica que la trayectoria de la enfermedad recrudece las formas de violencia (19); asimismo otro estudio cualitativo señala que las mujeres migrantes tienen dificultad para reconocer los actos de violencia sexual en sus cotidianeidades ${ }^{(18)}$.

A través de los estudios identificados se observa que la VG es analizada en todos los estudios desde la perspectiva de las víctimas, asimismo los estudios cuantitativos aluden a las formas de violencia generalizada (física, psicológica, económica y sexual) y no incluyen cuestiones específicas en las que se hace uso del VIH como forma de materialización de la violencia. Por otro lado, destaca que la mayor parte de los estudios sobre violencia en pareja y $\mathrm{VIH}$ excluyen también las situaciones de violencia intragénero ( $\mathrm{VI})$; es decir, la violencia que se produce en el seno de parejas del mismo sexo (homosexuales, lesbianas y bisexuales) o en parejas en la que alguno de sus miembros es transexual, transgénero o intersexual (20). En este sentido, revisiones sobre la VI como las de Saldivia, Faúndez, Sotomayor y Cea (21) y Rodríguez, Rodríguez-Castro, Lameiras y Carrera (20), evidencian que en este tipo de relaciones se producen situaciones en las que se hace uso del VIH como medio para materializar la violencia; bien a través del outing, el control, el contagio o la intimidación.

\section{OBJETIVOS}

\section{General}

Identificar la prevalencia y características de la violencia en pareja (perpetrador/a y receptor/a) en pacientes seropositivos adscritos al Instituto Mexicano del Seguro Social (IMSS) de Nuevo León (México).

\section{Específicos}

Construir y validar una escala que permita medir el uso del VIH como forma de ejercer la violencia en pareja (perpetrador/a y receptor/a). 
Analizar la prevalencia de la violencia física, psicológica, económica, sexual y a través del VIH, en pacientes seropositivos víctimas y agresores de VG y VI.

Identificar la relación existente entre la violencia en pareja, el tipo de apego y el nivel de satisfacción con la vida de los pacientes con VIH. Así como comparar los resultados en función al sexo, orientación sexual y seroprevalencia de la pareja.

\section{MATERIAL Y MÉTODO}

Estudio descriptivo, transversal y analítico llevado a cabo entre diciembre de 2019 y febrero de 2020 en el Estado de Nuevo León.

\section{Participantes}

El departamento de infectología de la zona norte del Instituto Mexicano del IMSS, tiene una cartera de 850 pacientes seropositivos que reciben tratamiento antirretroviral (universo). Se utilizó un muestreo probabilístico aleatorio simple con un margen de error del 5\% y nivel de confianza del $95 \%$ para seleccionar una muestra de 265 pacientes. Una vez obtenidos los 265 cuestionarios se realizó un proceso de selección para incluir los que estaban completos, obteniendo una muestra de 198 pacientes.

\section{Instrumentos}

Para la recolección de datos se aplicó un cuestionario anónimo autoadministrado en el que se incluyeron una batería de preguntas relativas a la identificación de datos sociodemográficos de la muestra, así como: (a) la escala Likert de tipo de apego (seguro, preocupado, temeroso y evitante) de 18 preguntas con valores de 1 a 5 de Padilla y Díaz-Loving (10), (b) la escala likert de satisfacción con la vida de Pons, Atienza, Balaguer y García-Merita ${ }^{(22)}$ formada por 5 reactivos con valores de 1 a 5 , (c) la escala likert de violencia en la relación de pareja (perpetrador/a y receptor/a) de Cienfuegos ${ }^{(23)}$ de 12 y 28 ítems respectivamente con valores de 1 a 5 y (d) la escala likert del uso del $\mathrm{VIH}$ como vía de materialización de la violencia (perpetrador/a y receptor/a) con valores de 1 a 5 (ver Anexo I).

\section{Procedimiento}

La recogida de datos se realizó en las inmediaciones del hospital, para ello en cada consulta la trabajadora social adscrita al departamento presentó la investigación a cada paciente y solicitó su participación de forma voluntaria. Una vez recogidos los cuestionarios se revisaron e incluyen los que estaban completos, los cuales se codificaron en una base de datos a través del programa SPSS para su posterior análisis.

\section{Análisis de los datos}

En primer lugar se procedió a la validación de la escala likert del uso del VIH como vía de materialización de la violencia (perpetrador/a y receptor/a), para ello se realizó el análisis propuesto por Zamalloa ${ }^{(24)}$, el cual consiste en cálculo del indicador de 
homogeneidad $(>0,20)$ de los ítems y en análisis de la confiabilidad por los métodos de separación de mitades y de covarianza de los ítems (alfa de Cronbach). A continuación, se realizó una comparación de medias y la prueba de t-student para muestras independientes con un porcentaje de intervalo de confianza del $95 \%$ de las escalas en base a las variables de análisis (pareja seropositiva y orientación sexual). Así como tablas cruzadas y la prueba de chi cuadrado respecto a cada una de la formas de violencia. También se realizó un análisis correlacional de Pearson a nivel 0.01 y 0.05 entre las escalas.

\section{Tratamiento de los datos}

Para la realización del estudio se aplicó la Norma que establece la disposición para la investigación en salud en el Instituto Mexicano del Seguro Social 2000-001-009 (25); así como la Ley General de Salud en Materia de Investigación para la Salud, la cual está basada en la Declaración de Helsinki. Así los cuestionarios se aplicaron de forma voluntaria, previa explicación sobre el objeto del estudio y la anonimización del mismo.

\section{RESULTADOS}

\section{Características de la muestra}

Las principales características sociodemográficas de la población objeto de estudio se presentan en la tabla 1 . Como puede observarse, la muestra final resultante la conforman 198 pacientes, con edades comprendidas entre los 20 y los 70 años (media=38.45 años), de los cuales la mayor parte son hombres (86.4), mexicanos/as (99.0\%), del Estado de Nuevo León (67.2\%), de contexto urbano (80.8\%), soleteros/as $(72.7 \%)$, sin hijos/as $(81.8 \%)$, homosexuales $(64.6 \%)$, con estudios medios $(47.0 \%)$, empleados/as $(87.9 \%)$, con un nivel socioeconómico declarado medio $(83.3 \%)$, no consumidores de drogas $(94.4 \%)$, cuya principal vía de contagio del $\mathrm{VIH}$ es la sexual $(75.3 \%)$, no participantes en grupos de apoyo para personas seropositivas $(93.4 \%)$, que nunca ha abandonado el tratamiento $(78.3 \%)$ y que no ha presentado dificultades para acceder al tratamiento $(66.7 \%)$.

\section{Validación de la Escala likert del uso del VIH como vía de materialización de la violencia (perpetrador/a y receptor/a)}

En el análisis ítem-test bajo, tal y como se muestra en la tabla 2, el indicador de homogeneidad indica que en la escala de perpetrador/a y en las escalas de receptor/a y perpetrador/a de la violencia en pareja a través del uso del $\mathrm{VIH}$, en todos los ítems el nivel de significancia es menor a lo permitido $(<0,05)$. No obstante, destaca que el ítem 3 de la escala del uso del VIH como vía de materialización de la violencia como receptor/a (Mi pareja me ha impedido ir al doctor o a la clínica), así como el ítem 4 en la escala de perpetrador/a (He impedido a mi pareja tomar la medicación), no se puede calcular porque al menos una variable es constante.

Asimismo, como se observa en la tabla 2 entre las diferentes dimensiones de la Escala Receptor/a de la violencia en pareja se producen correlaciones bilaterales de Pearson significativas al nivel 0,01 y una significancia menor a 0,05 con la Escala uso 
VIH Receptor/a; así como entre las dimensiones de la Escala Perpetrador/a de la violencia en pareja y la Escala uso VIH Perpetrador/a.

Por otro lado, en cuanto a confiabilidad los resultados del método de separación de mitades y de covarianza de los ítems (alfa de Cronbach), como se observa en la tabla 2 muestran unos resultados que revelan la existencia de un nivel de confiabilidad y consistencia interna aceptables. Es por ello que se considera conveniente incluir los 5 ítems de las escalas de perpetrador/a y receptor/a de la violencia en pareja a través del VIH (ver Anexo I) a las escalas de Cienfuegos (23).

Tabla 1. Características sociodemográficas de la muestra

\begin{tabular}{|c|c|c|c|}
\hline & & $\mathbf{N}$ & $\%$ \\
\hline \multirow{2}{*}{ Sexo } & Hombre & 171 & 86.4 \\
\hline & Mujer & 27 & 13.6 \\
\hline \multirow{2}{*}{ Nacionalidad } & Mexicana & 196 & 99.0 \\
\hline & Otra & 2 & 1.0 \\
\hline \multirow{2}{*}{ Lugar de origen } & Nuevo León & 133 & 67.2 \\
\hline & Otra & 65 & 32.8 \\
\hline \multirow{2}{*}{ Ámbito } & Rural & 38 & 19.2 \\
\hline & Urbano & 160 & 80.8 \\
\hline \multirow{5}{*}{ Estado civil } & Soltero/a & 144 & 72.7 \\
\hline & Casado/a & 38 & 19.2 \\
\hline & Separado/a & 2 & 1.0 \\
\hline & Divorciado/a & 3 & 1.5 \\
\hline & Viudo/a & 11 & 5.6 \\
\hline \multirow{4}{*}{ Pareja con VIH } & $\mathrm{Si}$ & 48 & 24.2 \\
\hline & No & 85 & 42.9 \\
\hline & NC & 3 & 1.5 \\
\hline & No aplica & 62 & 31.3 \\
\hline \multirow{2}{*}{ Múltiples parejas sexuales } & $\mathrm{Si}$ & 21 & 10.6 \\
\hline & No & 177 & 89.4 \\
\hline \multirow{2}{*}{ Hijos/as } & $\mathrm{Si}$ & 36 & 18.2 \\
\hline & No & 162 & 81.8 \\
\hline \multirow{4}{*}{ Orientación sexual } & Heterosexual & 49 & 24.7 \\
\hline & Homosexual & 128 & 64.6 \\
\hline & Bisexual & 20 & 10.1 \\
\hline & Otra & 1 & .5 \\
\hline \multirow{5}{*}{ Nivel de estudios máximos finalizados } & Primaria & 4 & 2.0 \\
\hline & Secundaria & 40 & 20.2 \\
\hline & Preparatoria & 53 & 26.8 \\
\hline & Universidad & 89 & 44.9 \\
\hline & Otros & 12 & 6.1 \\
\hline \multirow{5}{*}{ Situación laboral } & Trabajo & 174 & 87.9 \\
\hline & Estudio & 6 & 3.0 \\
\hline & Jubilado/a & 1 & .5 \\
\hline & En desempleo & 11 & 5.6 \\
\hline & Otro & 6 & 3.0 \\
\hline \multirow{3}{*}{ Estatus económico } & Bajo & 26 & 13.1 \\
\hline & Medio & 165 & 83.3 \\
\hline & Alto & 7 & 3.5 \\
\hline \multirow{5}{*}{ Vía contagio VIH } & Sexual & 149 & 75.3 \\
\hline & Drogas & 3 & 1.5 \\
\hline & Vía materna & 2 & 1.0 \\
\hline & Transfusión de sangre & 3 & 1.5 \\
\hline & Desconoce la vía & 41 & 20.7 \\
\hline \multirow[t]{2}{*}{ Consumo de drogas } & $\mathrm{Si}$ & 11 & 5.6 \\
\hline & No & 187 & 94.4 \\
\hline
\end{tabular}




\begin{tabular}{|c|c|c|c|}
\hline \multirow{2}{*}{ Grupo de apoyo VIH } & $\mathrm{Si}$ & 13 & 6.6 \\
\hline \multirow{2}{*}{ Abandono tratamiento } & $\mathrm{No}$ & 185 & 93.4 \\
\hline \multirow{2}{*}{ Dificultades acceso al tratamiento } & $\mathrm{Si}$ & 43 & 21.7 \\
\cline { 2 - 4 } & $\mathrm{No}$ & 155 & 78.3 \\
\hline & $\mathrm{Si}$ & 66 & 33.3 \\
\hline
\end{tabular}

Tabla 2. Correlaciones ítem-test, correlaciones entre escalas y dimensiones y estadísticos de confiabilidad y consistencia interna de ambas escalas

\begin{tabular}{|c|c|c|c|c|c|c|c|c|}
\hline \multirow{2}{*}{$\begin{array}{l}\text { Correlaciones } \\
\text { Item-test }\end{array}$} & \multicolumn{2}{|c|}{$\begin{array}{c}\text { Escala uso VIH } \\
\text { Receptor/a }\end{array}$} & \multirow{2}{*}{\multicolumn{2}{|c|}{$\begin{array}{l}\text { Correlaciones } \\
\text { Item-test }\end{array}$}} & \multicolumn{4}{|c|}{ Escala uso VIH Perpetrador/a } \\
\hline & $\begin{array}{l}\text { Pearson } \\
\text { Corr. }\end{array}$ & $\begin{array}{l}\text { Sig. } \\
(2- \\
\text { tailed })\end{array}$ & & & \multicolumn{2}{|c|}{ Pearson Corr. } & \multicolumn{2}{|c|}{ Sig. (2-tailed) } \\
\hline Receptor 1 & $.787\left(^{* *}\right)$ & .000 & \multicolumn{2}{|c|}{ Perpetrador/a 1} & \multicolumn{2}{|c|}{$.579\left({ }^{* *}\right)$} & \multicolumn{2}{|c|}{.000} \\
\hline Receptor 2 & $\left..486{ }^{* *}\right)$ & .000 & \multicolumn{2}{|c|}{ Perpetrador/a 2} & \multicolumn{2}{|c|}{$\left..563^{(* *}\right)$} & \multicolumn{2}{|c|}{.000} \\
\hline Receptor 3 & (a) &. & \multicolumn{2}{|c|}{ Perpetrador/a 3} & \multicolumn{2}{|c|}{$\left..5633^{* *}\right)$} & \multicolumn{2}{|c|}{.000} \\
\hline Receptor 4 & $.228\left(^{* *}\right)$ & .001 & \multicolumn{2}{|c|}{ Perpetrador/a 4} & \multicolumn{2}{|c|}{.(a) } & \multicolumn{2}{|c|}{. } \\
\hline Receptor 5 & $.808\left(^{* *}\right)$ & .000 & Perpetra & lor/a 5 & .133 & & .00 & \\
\hline \multirow{2}{*}{$\begin{array}{l}\text { Correlaciones } \\
\text { dimensiones }\end{array}$} & \multicolumn{2}{|c|}{$\begin{array}{c}\text { Escala } \\
\text { Receptor/a de la } \\
\text { violencia en } \\
\text { pareja }\end{array}$} & \multicolumn{2}{|c|}{$\begin{array}{c}\text { Escala uso VIH } \\
\text { Receptor/a }\end{array}$} & \multicolumn{2}{|c|}{$\begin{array}{c}\text { Escala } \\
\text { Perpetrador/a de } \\
\text { la violencia en } \\
\text { pareja }\end{array}$} & \multicolumn{2}{|c|}{$\begin{array}{l}\text { Escala uso VIH } \\
\text { Perpetrador/a }\end{array}$} \\
\hline & $\begin{array}{l}\text { Pearson } \\
\text { Corr. }\end{array}$ & $\begin{array}{l}\text { Sig. } \\
(2- \\
\text { tailed })\end{array}$ & $\begin{array}{l}\text { Pearson } \\
\text { Corr. }\end{array}$ & $\begin{array}{l}\text { Sig. } \\
(2- \\
\text { tailed })\end{array}$ & $\begin{array}{c}\text { Pearson } \\
\text { Corr. }\end{array}$ & $\begin{array}{l}\text { Sig. (2- } \\
\text { tailed) }\end{array}$ & $\begin{array}{l}\text { Pearson } \\
\text { Corr. }\end{array}$ & $\begin{array}{l}\text { Sig. } \\
(2- \\
\text { tailed })\end{array}$ \\
\hline V. Psicológica & $.979\left(^{* *}\right)$ & .000 & $.491\left(^{* *}\right)$ & .000 & $.948\left(^{* *}\right)$ & .000 & $.344\left({ }^{* *}\right)$ & .000 \\
\hline V. Física & $\left..7211^{(*}\right)$ & .000 & $.212\left(^{* *}\right)$ & .003 & $.558\left({ }^{* \star}\right)$ & .000 & $\left..4499^{* *}\right)$ & .000 \\
\hline V. Económica & $.767\left(^{* *}\right)$ & .000 & $.336\left(^{* *}\right)$ & .000 & $.605\left(^{* \star}\right)$ & .000 & $.430\left(^{* *}\right)$ & .000 \\
\hline V. Sexual & $\left..7933^{(*}\right)$ & .000 & $.424\left(^{* *}\right)$ & .000 & $.637\left(^{* *}\right)$ & .000 & $\left..391{ }^{* *}\right)$ & .000 \\
\hline V. VIH & $\left..4799^{(* *}\right)$ & .000 & 1 & & $.456\left(^{* *}\right)$ & .000 & $\left..3911^{* *}\right)$ & .000 \\
\hline $\begin{array}{c}\text { Escala } \\
\text { Receptor/a de la } \\
\text { violencia en } \\
\text { pareja }\end{array}$ & 1 & & $.479\left(^{* *}\right)$ & .000 & $.488\left({ }^{* *}\right)$ & .000 & $\left..190{ }^{* *}\right)$ & .007 \\
\hline \multirow[t]{2}{*}{$\begin{array}{c}\text { Escala } \\
\text { Perpetrador/a } \\
\text { de la violencia } \\
\text { en pareja }\end{array}$} & $.488\left(^{* *}\right)$ & .000 & $.306\left(^{* \star}\right)$ & .000 & 1 & & $.456\left(^{* *}\right)$ & .000 \\
\hline & & & & & \multicolumn{2}{|c|}{$\begin{array}{c}\text { Escala } \\
\text { Receptor/a + } \\
\text { Receptor VIH }\end{array}$} & \multicolumn{2}{|c|}{$\begin{array}{c}\text { Escala } \\
\text { Perpetrador/a + } \\
\text { Perpetrador/a VIH }\end{array}$} \\
\hline \multirow{6}{*}{ Confiabilidad } & \multirow{2}{*}{\multicolumn{2}{|c|}{ Alfa de Cronbach }} & \multicolumn{2}{|c|}{ Parte 1} & \multicolumn{2}{|c|}{.921} & \multicolumn{2}{|c|}{.831} \\
\hline & & & \multicolumn{2}{|c|}{ Parte 2} & .77 & & .75 & \\
\hline & & relación & ntre forma & & .81 & & .57 & \\
\hline & Coeficie & te de & Longitu & igual & .85 & & .73 & \\
\hline & Spearma & -Brown & L. des & gual & .89 & & .73 & \\
\hline & & mitades & de Guttma & & .75 & & $.5 \varepsilon$ & \\
\hline Consistencia & & Alfa de $C$ & conbach & & .93 & & .8 & \\
\hline interna & & $\mathrm{N}^{\circ}$ de el & mentos & & 3 & & 1 & \\
\hline
\end{tabular}

Nota: ${ }^{* *}$ La correlación es significativa al nivel 0,01 (bilateral). a No se puede calcular porque al menos una variable es constante. 


\section{Análisis de la escala violencia en la relación de pareja (perpetradorla y receptor/a) y de la escala del uso del VIH como vía de materialización de la violencia}

Los resultados obtenidos a través de la aplicación de la escala de receptor/a de la violencia, se observa que 80 participantes $(40.40 \%)$ manifiestan haber vivenciado situaciones de violencia por parte de su pareja. También se advierte que 75 pacientes señalan haber sido víctimas de violencia psicológica $(37.87 \%), 41$ de violencia sexual (20.70\%), 24 de violencia física (12.12\%), 22 de violencia económica $(11.11 \%)$ y 9 de violencia a través del uso del VIH (4.54\%). En este sentido, tal y como se observa en el Anexo II, las expresiones de violencia más referidas son el ítem 6 (Mi pareja vigila todo lo que yo hago) con 48 participantes (24.21\%), el ítem 8 (Mi pareja no toma en cuenta mis necesidades sexuales) y el ítem 22 (Mi pareja se pone celoso(a) y sospecha de mis amistades) con 38 pacientes respectivamente y el ítem 3 (Mi pareja se enoja conmigo si no hago lo que quiere) con 35 (17.7\%). Asimismo, cabe destacar que tras realizar la prueba de chi-cuadrado el resultado de la significación asintótica en todos los ítems obtuvo un valor superior a 0.05 . Respecto a las cuestiones referentes al uso del VIH como medio de materialización de la violencia, se advierte que la forma más reportada es el ítem 2 (Mi pareja me ha ocultado que tenía VIH y me ha contagiado); el cual es referido por el $2.5 \%$ de la muestra.

Por otro lado, en cuanto a la escala de perpetrador/a de la violencia se identifican 81 participantes $(40.90 \%)$ que manifiestan haber ejercido violencia hacia su pareja; de los cuales 78 pacientes señalan haber realizado violencia psicológica $(39.39 \%), 31$ violencia sexual (15.65\%), 15 violencia económica $(7.57 \%), 9$ violencia física $(4.54 \%)$ y 5 violencia a través del uso del VIH (2.52\%). En este sentido, tal y como se observa en el Anexo II, las expresiones de violencia más referidas son el ítem 3 (Me he enojado cuando me contradice o no está de acuerdo conmigo) con 68 participantes (34.30\%), el ítem 2 (He llegado a gritarle a mi pareja) con 62 pacientes $(31.30 \%$ ) y el ítem 4 (He llegado a insultar a mi pareja) con 34 (17.20\%). Asimismo, cabe destacar que tras realizar la prueba de chi-cuadrado el resultado de la significación asintótica en todos los ítems obtuvo un valor superior a 0.05 . Respecto a las cuestiones referentes al uso del VIH como medio de materialización de la violencia, se advierte que la forma más reportada es el ítem 1 (He amenazado a mi pareja con decir a otras personas que tengo $\mathrm{VIH}$ ); el cual es referido por el $1.0 \%$ de la muestra.

Asimismo, cabe destacar que la frecuencia en las formas de materialización de la violencia los 81 agresores/as se corresponde con valores medios (media=2.750; $\mathrm{DT}=1.109$ ), superiores respecto a la violencia sexual y la violencia en la que se hace uso del VIH. Mientras que, respecto a las 80 víctimas la frecuencia es ligeramente inferior, aunque evidencia también valores medios (media=2.693; DT=0.660); superiores respecto a la violencia sexual y psicológica (ver tabla 3).

\section{Análisis en función a las variables del sexo, orientación sexual y estatus de seropositividad de la pareja}

Tomando en consideración las variables relativas al sexo, orientación sexual y estatus de seropositividad de la pareja se identifican las siguientes peculiaridades:

- Respecto a la variable relativa al sexo se observa que 70 hombres $(30.03 \%)$ y 10 mujeres $(66.66 \%)$ manifiestan haber sido víctimas por parte de su pareja, de 
los cuales 6 hombres (3.05\%) y 3 mujeres (18.51\%) sufrieron violencia a través del uso del VIH. En cuanto a la muestra que señala que ejerció violencia hacia sus parejas, se identifican 69 hombres $(40.35 \%)$ y 12 mujeres $(44.44 \%)$, de los cuales 3 hombres $(1.75 \%)$ y 2 mujeres $(7.70 \%)$ manifestaron haber utilizado el $\mathrm{VIH}$ como medio para ejercer la violencia. Por otro lado, destaca que la frecuencia de la violencia en receptores/as hombres (media=2.63) es ocasional y en mujeres (media=1.90) esporádica, así como cada una de sus formas de materialización; a excepción de la violencia económica, la cual es superior en mujeres. En cuanto a la escala de perpetrador/a de la violencia se advierte una mayor frecuencia en hombres (media=2.68) que en mujeres (media=1.96), así como cada una de sus formas de materialización. Asimismo, destaca que tras la realización de la prueba t-student la significación bilateral de cada una de las dimensiones es superior a 0.05 (ver tabla 3).

- Por otro lado, tomando en consideración el estatus de seropositividad de la pareja, se observa que 32 participantes con pareja seropositiva (66.66\%) y 43 con pareja serodiscordante $(50.58 \%)$ manifiestan haber sido víctimas por parte de su pareja; de los cuales 6 serodiscordante $(6.25 \%)$ y 3 seropositivas $(5.88 \%)$ sufrieron violencia a través del uso del $\mathrm{VIH}$. En cuanto a la muestra que señala que ejerció violencia hacia sus parejas, se identifican 33 participantes con pareja seropositiva $(68.75 \%$ ) y 41 con pareja serodiscordante (48.23\%), de los cuales 2 seropositiva $(4.16 \%)$ y 3 serodiscordante $(3.52 \%)$ manifestaron haber utilizado el VIH como medio para ejercer la violencia. Por otro lado, destaca que la frecuencia de la violencia en receptores/as de parejas serodiscordantes (media=2.64) es ocasional, al igual que en las seroprevalentes (media=2.37), aunque ligeramente superior en las primeras; así como cada una de sus formas de materialización. En cuanto a la escala de perpetrador/a de la violencia se advierte una mayor frecuencia en parejas serodiscordantes (media=2.32) que en seroprevalentes (media=2.02), así como cada una de sus formas de materialización. Asociándose en cada caso a una violencia ocasional. Asimismo, destaca que tras la realización de la prueba tstudent la significación bilateral de cada una de las dimensiones es superior a 0.05 (ver tabla 3).

- Finalmente, respecto a la orientación sexual se observa que 16 participantes heterosexuales $(32.65 \%$ ) y 64 no heterosexuales $(49.95 \%)$ manifiestan haber sido víctimas por parte de su pareja; de los cuales 2 heterosexuales $(4.08 \%)$ y 7 no heterosexuales $(4.69 \%)$ sufrieron violencia a través del uso del VIH. En cuanto a la muestra que señala que ejerció violencia hacia sus parejas, se identifican 16 participantes heterosexuales $(32.65 \%)$ y 65 no heterosexuales $(43.62 \%)$, de los cuales 2 heterosexuales $(4.08 \%)$ y 3 no heterosexuales $(2.01 \%)$ manifestaron haber utilizado el $\mathrm{VIH}$ como medio para ejercer la violencia. Por otro lado, destaca que la frecuencia de la violencia en receptores/as heterosexuales (media $=2.65$ ) es ocasional, al igual que en no heterosexuales (media=2.63) y ligeramente superior en la muestra heterosexual; así como cada una de sus formas de materialización a excepción de la violencia a través del uso del VIH. En cuanto a la escala de perpetrador/a de la violencia se advierte una mayor frecuencia en no heterosexuales (media=2.32) que en heterosexuales (media=1.98), así como cada una de sus formas de materialización a excepción de la violencia psicológica. Asimismo, 
destaca que tras la realización de la prueba t-student la significación bilateral de cada una de las dimensiones es superior a 0.05 (ver tabla 3).

Tomando en consideración los resultados obtenidos en las escalas de tipos de apego y satisfacción con la vida, como se observa en la tabla 4, los resultados advierten que la muestra de nivel de satisfacción con la vida medio-alto (media=3.54; DT=1.11); superior en hombres, pacientes no heterosexuales y participantes con pareja seroprevalente. Asimismo, se identifica que el apego con mayor calado en la muestra es el de tipo seguro (media=2.58; DT=.931); el cual es superior en mujeres, pacientes no heterosexuales y en parejas serodiscordantes.

Finalmente cabe destacar que las escalas de perpetrador/a y receptor/a de la violencia en pareja (incluidos los ítems del uso del VIH como medio de materialización de la violencia), son directamente proporcionales con la escala de apego seguro (Correlación de Pearson Receptor/a $=.014$ y Sig.= .848; Correlación de Pearson Perpetrador/a $=.011$; Sig. $=.879)$ e inversamente proporcionales con la escala de satisfacción con la vida (Correlación de Pearson Receptor/a=-.007 y Sig.= 198; Correlación de Pearson Perpetrador/a=.826; Sig.= 198); aunque no se aprecian correlaciones de Pearson a nivel 0.01 y 0.05 entre las mismas.

Tabla 3. Comparación de medias escala de violencia según variables de análisis.

\begin{tabular}{|c|c|c|c|c|c|c|c|c|c|c|c|c|c|c|c|}
\hline \multirow{3}{*}{\multicolumn{2}{|c|}{ Escala }} & \multirow{2}{*}{\multicolumn{2}{|c|}{ Total }} & \multicolumn{4}{|c|}{ Pareja seropositiva } & \multicolumn{4}{|c|}{ Sexo } & \multicolumn{4}{|c|}{ Orientación sexual } \\
\hline & & & & \multicolumn{2}{|c|}{$\begin{array}{c}\mathrm{Si} \\
(\mathrm{n}=48)\end{array}$} & \multicolumn{2}{|c|}{$\begin{array}{c}\text { No } \\
(n=85)\end{array}$} & \multicolumn{2}{|c|}{$\begin{array}{l}\text { Hombre } \\
(n=171)\end{array}$} & \multicolumn{2}{|c|}{$\begin{array}{l}\text { Mujer } \\
(\mathrm{n}=27)\end{array}$} & \multicolumn{2}{|c|}{$\begin{array}{l}\text { Hetero } \\
(n=49)\end{array}$} & \multicolumn{2}{|c|}{$\begin{array}{c}\text { LGBQ } \\
(n=149)\end{array}$} \\
\hline & & $\bar{x}$ & $\sigma$ & $\bar{x}$ & $\sigma$ & $\overline{\mathrm{x}}$ & $\sigma$ & $\overline{\mathrm{x}}$ & $\sigma$ & $\overline{\mathrm{x}}$ & $\sigma$ & $\overline{\mathrm{x}}$ & $\sigma$ & $\overline{\mathrm{x}}$ & $\sigma$ \\
\hline \multirow{6}{*}{ 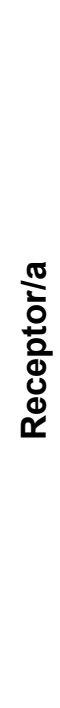 } & Psic. & 2.75 & 0.25 & 2.54 & .32 & 2.81 & .35 & 2.79 & .27 & 2.03 & .87 & 2.86 & .55 & 2.75 & .25 \\
\hline & Físi. & 2.53 & 0.21 & 2.24 & .21 & 2.40 & .40 & 2.71 & .20 & 2.11 & .19 & 3.11 & .14 & 2.35 & .32 \\
\hline & Eco. & 2.54 & 0.47 & 2.54 & .73 & 2.33 & .30 & 2.65 & .54 & 2.33 & .74 & 2.75 & 1.14 & 2.48 & .38 \\
\hline & Sex. & 2.97 & 0.01 & 1.89 & 1.64 & 2.60 & 1.21 & 2.99 & .01 & 1.66 & 1.52 & 3.25 & .68 & 2.90 & .15 \\
\hline & VIH & 2.63 & 1.66 & 2.00 & 2.73 & 2.10 & 2.13 & 1.90 & 2.60 & 1.00 & 1.29 & 1.00 & 1.41 & 2.48 & 2.32 \\
\hline & Total & 2.69 & 0.66 & 2.37 & 1.14 & 2.64 & .95 & 2.63 & 1.02 & 1.90 & 1.01 & 2.65 & .97 & 2.63 & .87 \\
\hline \multirow{2}{*}{$\begin{array}{l}\frac{\pi}{0} \\
\frac{0}{0} \\
\frac{\pi}{0} \\
\frac{0}{0} \\
\frac{0}{0} \\
0\end{array}$} & Psic & 2.53 & 0.11 & 2.33 & .32 & 2.29 & .09 & 2.43 & .21 & 2.41 & .22 & 2.77 & .35 & 2.14 & .22 \\
\hline & Fís. & 2.44 & 0.20 & 2.00 & .34 & 2.25 & .20 & 2.50 & .27 & 2.33 & .28 & 2.00 & .19 & 2.57 & .40 \\
\hline
\end{tabular}




\begin{tabular}{|l|l|l|l|l|l|l|l|l|l|l|l|l|l|l|}
\hline Eco. & 2.52 & 0.19 & 2.23 & .13 & 2.75 & .11 & 2.53 & .24 & 2.50 & 0 & 2.50 & 0 & 2.53 & .24 \\
\hline Sex. & 3.01 & 0.33 & 2.69 & .43 & 3.22 & .39 & 3.01 & .32 & 1.33 & 1.88 & 1.62 & 2.29 & 2.97 & .38 \\
\hline VIH & 3.10 & 2.13 & 1.40 & 2.19 & 1.40 & 2.19 & 3.00 & 2.73 & 1 & 1.09 & 1 & 1.09 & 3 & 2.73 \\
\hline Total & 2.75 & 1.10 & 2.07 & 1.21 & 2.32 & 1.28 & 2.68 & 1.40 & 1.96 & 1.57 & 1.98 & 1.20 & 2.69 & 1.40 \\
\hline
\end{tabular}

Nota: $\overline{\mathrm{x}}=$ media; $\sigma=$ desviación estándar.

Tabla 4. Comparación de medias escala apego y satisfacción con la vida según variables de análisis

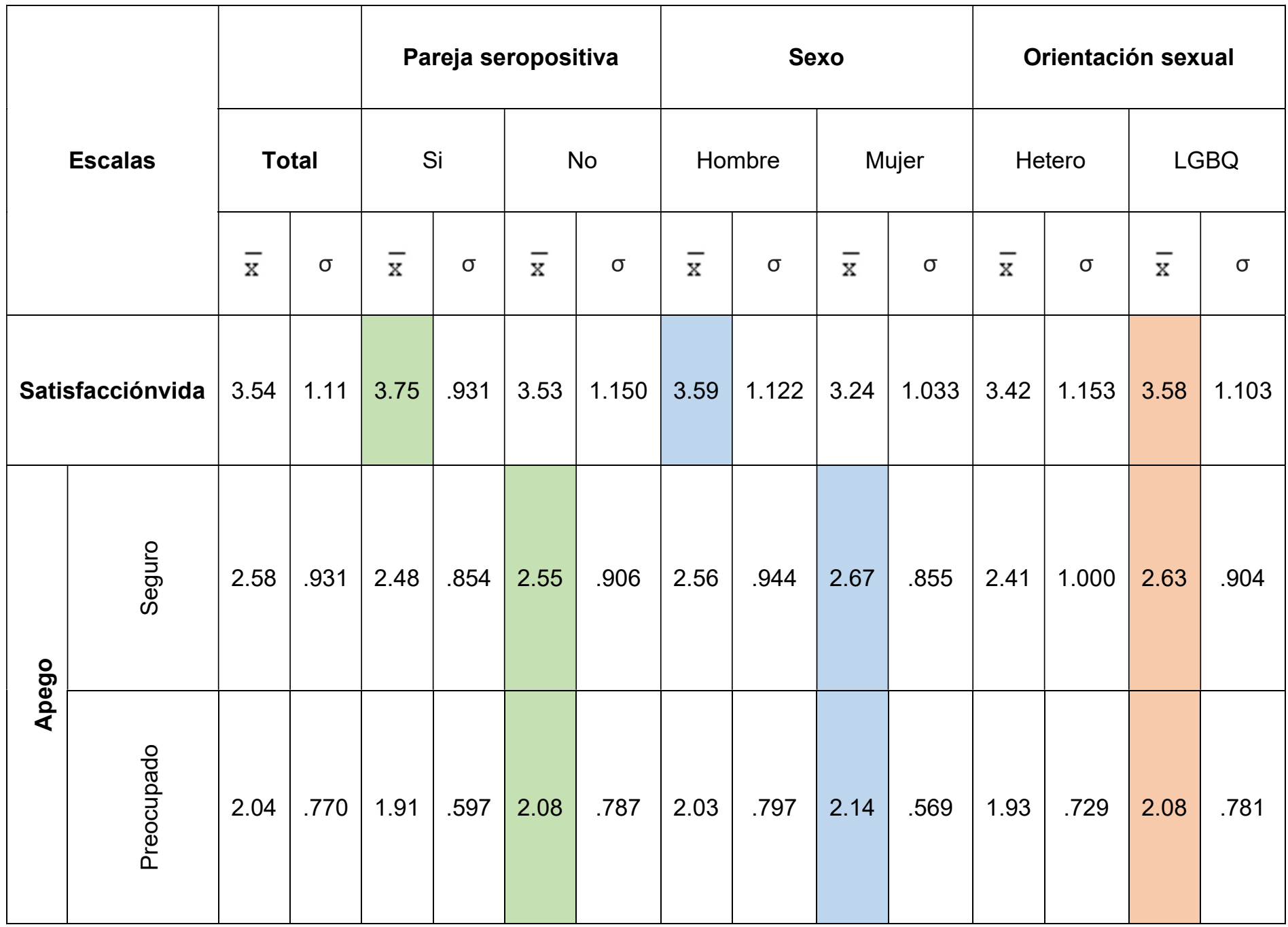




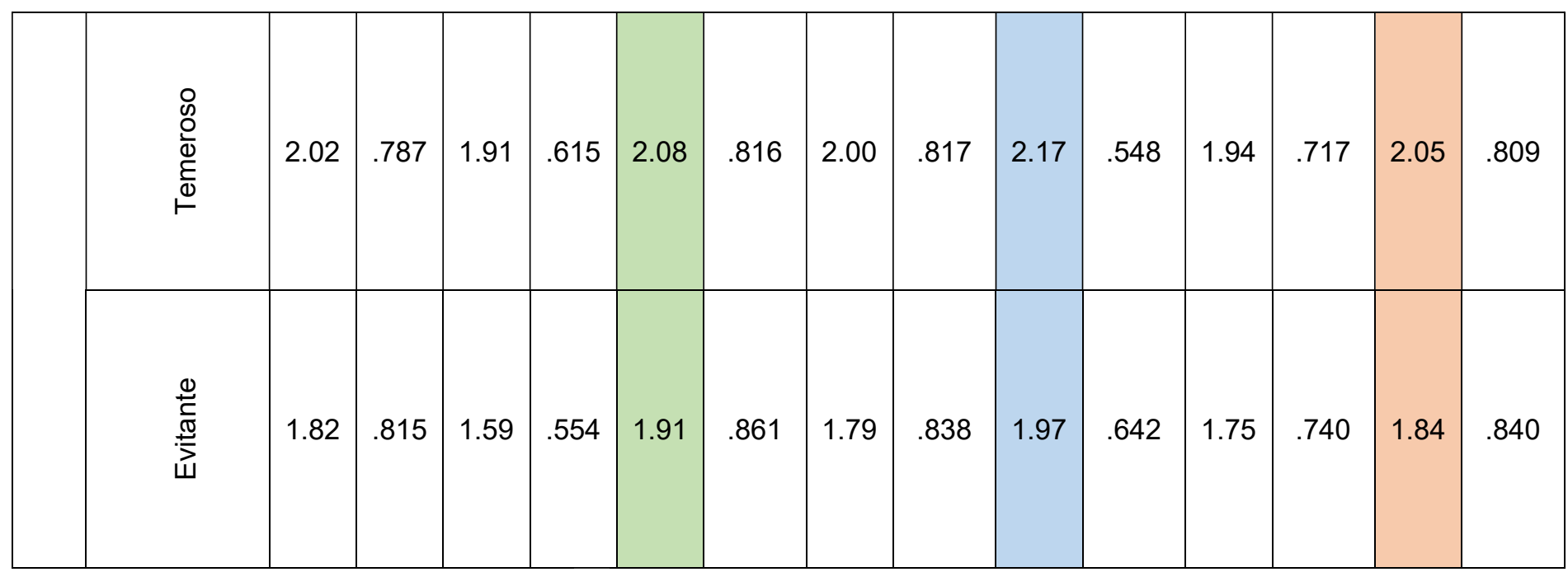

Nota: $\overline{\mathrm{x}}=$ media; $\sigma=$ desviación estándar.

\section{DISCUSIÓN}

A través de la presente investigación se ha constatado que, en el contexto regiomontano, existe una prevalencia de violencia en pareja en la que alguno de sus miembros es seropositivo del $40.40 \%$. Comparando este resultado con otras investigaciones, se observa que la prevalencia es superior a estudios contextualizados en Colombia (8) y Brasil (15); e inferior a otras contextualizadas en Chile ${ }^{(18)}$ y Brasil (14). No obstante, cabe destacar que, en dichas investigaciones, la muestra estaba conformada solamente pon mujeres. También se observa que la violencia psicológica, al igual que en la investigación realizada por Vidal, Carrasco y Pascal en México sobre VG ${ }^{(18)}$, es la principal vía de materialización (37.87\%); seguido de la violencia sexual $(20.70 \%)$, la violencia física $(12.12 \%)$, la violencia económica (11.11\%) y la violencia en la que se hace uso del VIH como medio para materializarla (4.54\%). Asimismo, se ha constatado que existe una mayor proporción de víctimas mujeres, no heterosexuales, y de parejas en la que ambos miembros son seropositivos. No obstante, se advierte que existe una mayor frecuencia en el tiempo cuando las víctimas son hombres, heterosexuales y en parejas serodiscordantes.

Por otro lado, a través de los resultados obtenidos se han registrado una prevalencia de agresores de violencia en pareja en la que alguno de sus miembros es seropositivo del $40.90 \%$. También se observa que la violencia psicológica es la principal vía de materialización (39.39\%), seguido de la violencia sexual (15.65\%), la violencia económica $(7.57 \%)$, la violencia física $(4.54 \%)$ y la violencia en la que se hace uso del VIH como medio para materializarla (2.52\%). Asimismo, se ha constatado que existe una mayor proporción de agresores/as mujeres, no heterosexuales y de parejas en la que ambos miembros son seropositivos. No obstante, se advierte que existe una mayor frecuencia en el tiempo cuando los agresores/as son hombres, no heterosexuales y en parejas serodiscordantes. Estos resultados no es posible compararlos con otras investigaciones, ya que no se han identificado estudios en los que se aborde la perspectiva del perpetrador/a de la violencia en este tipo de parejas. No obstante, cabe destacar que dicha prevalencia es semejante al descrito anteriormente respecto a las víctimas. Lo cual revela que en varios pacientes existe violencia bidireccional; por lo que sería idóneo tener en cuanta en próximas 
investigaciones cuando la figura de perpetrador/a se manifiesta como defensa una agresión o forma de violencia.

También cabe destacar que los resultados evidencian que en parejas en la que alguno de sus miembros es seropositivo, además de existir VG como también se presenta en investigaciones precedentes $(1,2,11-13,16)$, existe tal y como advierten las revisiones bibliográficas de Rodríguez, Rodríguez-Castro, Lameiras y Carrera ${ }^{(20)}$ y Saldivia, Faúndez, Sotomayor y Cea ${ }^{(21)}$, violencia en parejas del mismo sexo (VI). De hecho, los resultados obtenidos revelan que en este tipo de relaciones es más frecuente la VI que la VG. No obstante, en la interpretación de los resultados, sería conveniente tener en cuenta que, como indican estudios realizados en Brasil (12), Argentina ${ }^{(17)}$ y México (18), las víctimas presentan dificultad para reconocer los actos de violencia (especialmente la violencia sexual). Asimismo, cabría considerar que como advierten estudios abordados en Argentina, las políticas públicas (16), la opresión racial y de género representan factores favorecedores de la violencia en pareja en este tipo de relaciones ${ }^{(17)}$. Por otro lado, se observa que la prevalencia de la violencia en pareja es mayor (tanto en perpetradores/as como en receptores/as) en parejas en la que ambos miembros son seropositivos que en parejas serodiscordantes. Lo cual podría justificarse por el estigma socialmente adscrito al virus, el cual como señalan diferentes autores coadyuva al sometimiento que las culturas patriarcales reproducen en torno a las mujeres $(3,4)$; y también de las identidades que difieren del modelo de masculinidad hegemónico.

Finalmente se ha comprobado que existe un mayor nivel de violencia, tanto en la forma de perpetración como de recepción de la violencia, en pacientes con mayor nivel de apego seguro (caracterizado por una alta valoración personal, la comodidad con la intimidad y por un elevado nivel de autonomía) y menor nivel de satisfacción con la vida (10). Este dato corrobora los manifestados en otra investigación en Colombia (11), en la cual se advierte que este tipo de situaciones tiene como consecuencia en las mujeres una baja autoestima, el daño autoimagen, la depresión y la culpabilización. No obstante, cabe señalan que en los resultados obtenidos no se aprecian correlaciones de Pearson a nivel 0.01 y 0.05 entre las distintas escalas y subescalas. Asimismo, es importante tener en cuenta que en dichos procesos también hay que considerar otros factores como las políticas públicas (16), los procesos de discriminación por cuestiones raciales (17), el estigma asociado al VIH/SIDA ${ }^{(3-5)}$.

\section{CONCLUSIONES}

Los resultados obtenidos en la presenta investigación muestran que, de los 198 pacientes seropositivos del departamento de infectología del Hospital General de Zona con Medicina Familiar $n^{\circ} 6$ del Instituto Mexicano del IMSS (Nuevo León), el $40.40 \%$ han sufrido violencia por parte de sus parejas y el $40.90 \%$ han ejercido violencia hacia sus parejas. También se ha constado que la violencia psicológica es la más frecuente y que existe una mayor prevalencia de este tipo de violencia en sendas formas (perpetrador/a y recpetor/a) en mujeres, pacientes no heterosexuales (LGB) y en parejas en la que ambos miembros son seropositivos. Asimismo se ha constado que la frecuencia en sendos perfiles es esporádica. 
En cuanto a la violencia en la que se hace uso del VIH como medio para materializarla se ha identificado que el $4.54 \%$ de la muestra señala que ha sido víctima de alguna de las formas analizadas en la escala validada; así como el $2.52 \%$ como perpetrador/a de las mismas. También se advierte que este tipo de manifestaciones de la violencia son más frecuentes en mujeres, personas no heterosexuales y en parejas serodiscordantes. Es importante toman en consideración los determinantes sociales que ejercen como factores favorecedores como: el machismo, el patriarcado, la discriminación de las personas por su orientación sexual y la estigmatización y la discriminación a personas con VIH entre otros. Asimismo, es importante tener en cuenta que como señalan diferentes autores, este conjunto de factores, representan los desencadenantes tanto de repercusiones sociales como de consecuencias para la salud física y psicosocial de las víctimas, incluida la disminución de linfocitos CD4+ y la adherencia al tratamiento.

\section{Agradecimiento}

Queremos dejar constancia del agradecimiento al Instituto Mexicano del IMSS de Nuevo León (México), a través del cual se ha conseguido distribuir el cuestionario a los pacientes.

\section{REFERENCIAS}

1. Kouyoumdjian FG, Findlay N, Schwandt M, Calzavara LM. A systematic review of the relationships between intimate partner violence and HIVIAIDS. PLoS One. 2013;8(11). Disponible en https://pubmed.ncbi.nlm.nih.gov/24282566/

2. Arévalo-Mora L. Violencia de pareja en la mujer que vive con VIH. Revista Colombiana de Enfermería. 2018;16(13): 52-63. Disponible en http://www.sidastudi.org/resources/inmagic-img/DD48695.pdf

3. Puente-Martínez A, Ubillos-Landa S, Echeburúa E, Páez-Rovira D. Factores de riesgo asociados a la violencia sufrida por la mujer en la pareja: una revisión de metaanálisis y estudios recientes. 2016;32(1):295-306. Disponible en http://scielo.isciii.es/scielo.php?script=sci_arttext\&pid=S0212-97282016000100034

4. Aggleton P, Parker R. World AIDS Campaign 2002-3. A Conceptual Framework and Basis for Action. HIVIAIDS Stigma and Discrimination. Ginebra: UNAIDS; 2002. Disponible en https://www.unaids.org/sites/default/files/media_asset/jc891wac_framework_en_0.pdf

5. Fraser N, Honneth A. Redistribución o reconocimiento. Madrid: Morata; 2006.

6. Alonso A, Cerezo A, Pagés RA, Ramos K, Torricelli V. Informe de situación sobre VIH y violencia basada en el género: una aproximación desde los determinantes sociales. Guatemala: ONUSIDA; 2011. Disponible en https://www.paho.org/gut/index.php?option=com docman\&view=download\&category sl ug=9-derechos-humanos-y-salud \&alias=445-informe-de-situacion-sobre-vih-y-violenciabasada-en-genero\&ltemid $=518$

7. Maeri I, El Ayadi A, Getahun M, Charlebois E, Akatukwasa C, Tumwebaze D, et ál. "How can I tell?" Consequences of HIV status disclosure among couples in eastern African communities in the context of an ongoing HIV "test-and-treat" trial. AIDS Care-Psychological and Socio-Medical Aspects of AIDS/HIV. 2016; 28(Suplemento 3):59-66. Disponible en https://www.tandfonline.com/doi/full/10.1080/09540121.2016.1168917

8. Arévalo-Mora L. Mujeres víctimas de violencia de pareja en el contexto de la infección por VIH en la ciudad de Bogotá. Fase I, 2017. Revista de Salud Pública. 
2019;

21(1):

34-41.

Disponible

en

http://www.scielo.org.co/scielo.php?script=sci_arttext\&pid=S0124-

00642019000100034

9. Márquez JF, Rivera S, Reyes I. Desarrollo de una escala de estilos de apego adulto para la población mexicana. Revista Iberoamericana de Diagnóstico y Evaluación Psicológica. 2009; 2(28): 9-30. Disponible en https://www.aidep.org/sites/default/files/2018-12/r281.pdf

10.Padilla JA, Díaz-Loving R. Evaluación del apego en adultos: construcción de una escala con medidas independientes. Enseñanza e Investigación en Psicología. 2016; 21(2): 161-168. Disponible en https://www.redalyc.org/pdf/292/29248181006.pdf

11.Arévalo-Mora L. Experiencias y narrativas de mujeres con vih. Víctimas de violencia de pareja en Bogotá (Colombia). Medicina. 2019; 41(4): 299-321. Disponible en https://revistamedicina.net/ojsanm/index.php/Medicina/article/view/1469

12.Rangel YY. La violencia sexual como limitante en la percepción y gestión de riesgo frente al VIH en mujeres parejas de migrantes. Revista Latino-Americana de Enfermagem. 2016; 24: 1-8. Disponible en http://dx.doi.org/10.1590/15188345.1141.2782

13.Drezett J, Baldacini I, Nisida IV, Nassif VC, Nápoli PC. Estudo da adesão à quimioprofilaxia anti-retroviral para a infecção por HIV em mulheres sexualmente vitimadas. Revista Brasileira de Ginecologia e Obstetrícia. 1999; 21(9): 539-544. Disponible en https://www.scielo.br/scielo. $p h p ?$ pid=S010072031999000900007\&script=sci_arttext

14.Barros C, Schraiber LB, França-Junior I. Association between intimate partner violence against women and HIV infection. Revista de saude publica. 2011; 45(2): 365-372. Disponible en http://dx.doi.org/10.1590/S0034-89102011005000008.

15.Porto JR, Homero MN, Luz AM. Violence against woman and the female increase of HIVIAIDS incidence. Online Braz J Nurs. 2003;2(3). Disponible en http://www.scielo.br/scielo.php?script=sci $n$ links\&ref=000118\&pid=S01032100201300020000900017\&lng=en

16. Blanco M, Armada F. Las mujeres no esperamos más: Acabemos la violencia contra la mujer y el VIH/SIDA ya. Buenos Aires: Publicación para América Latina y el Caribe; $2007 . \quad$ Disponible en http://www.feim.org.ar/pdf/LO QUE SE MIDE IMPORTA2008.pdf

17. Bianco M, Mariño A, Re MI. Violencia contra las mujeres y vih/sida en cuatro países del Mercosur. Estadísticas, políticas públicas, legislación y estado del arte. Ciudad de Buenos Aires: Fundación para Estudio e Investigación de la Mujer; 2009. Disponible en http://feim.org.ar/pdf/publicaciones/Informe Regional violencia.pdf

18.Vidal F, Carrasco M, Pascal R. Mujeres Chilenas viviendo con VIH/SIDA: derechos sexuales y reproductivos. Santiago de Chile: Vivo Positivo, FLACSO y Universidad ARCIS; $2004 . \quad$ Disponible en http://www.feim.org.ar/pdf/blog_violencia/chile/MujeresChilenas_con_VIH_y_DSyR. pdf

19.Juan-Martínez B, Rangel YY, Castillo-Arcos LD, Cacique L. Ser mujer indígena, vivir con VIH y violencia de pareja: una triple vulneración frente al derecho a la salud. Index de Enfermería. 2018; 27(3): 161-165. Disponible en http://scielo.isciii.es/scielo.php?script=sci_arttext\&pid=S1132-12962018000200012

20.Rodríguez LM, Rodríguez-Castro Y, Lameiras M, Carrera MV. Violencia en parejas Gays, Lesbianas y Bisexuales: una revisión sistemática 2002-2012. Comunitania: 
Revista Internacional de Trabajo Social y Ciencias Sociales. 2017; 13: 49-71. Disponible en http://revistas.uned.es/index.php/comunitania/article/view/18946/0

21.Saldivia C, Faúndez B, Sotomayor S, Cea, F. Violencia íntima en parejas jóvenes del mismo sexo en Chile. Última Década. 2017; (46):184-212. Disponible en https://scielo.conicyt.cl/pdf/udecada/v25n46/0718-2236-udecada-25-46-00184.pdf

22.Pons D, Atienza FL, Balaguer I, García-Merita ML. Propiedades psicométricas de la Escala de Satisfacción con la Vida en personas de la tercera edad. Revista Iberoamericana de Diagnóstico, Evaluación Psicológica. 2002; 13: 71-82. Disponible en https://psycnet.apa.org/record/2002-18447-005

23. Cienfuegos YI. Validación de dos versiones cortas para evaluar violencia en la relación de pareja: perpetrador/a y receptor/a. Psicología Iberoamericana. 2014; 22(1): 62-71. Disponible en https://www.redalyc.org/pdf/1339/133944229008.pdf

24. Zamalloa ER. Elaboración y validación de una escala de homofobia en estudiantes universitarios de una universidad privada de Lima Este. PsiqueMag. Revista Científica Digital de Psicología. 2017; 6(1): 245-255. Disponible en http://revistas.ucv.edu.pe/index.php/psiquemag/issue/view/214/Psiquemag\%20201 7-17

25. Instituto Mexicano del Seguro Social [IMSS]. Norma que establece la disposición para la investigación en salud en el Instituto Mexicano del Seguro Social 2000-001009; 2017.

Disponible

en http://www.imss.gob.mx/sites/all/statics/profesionalesSalud/investigacionSalud/normativi dadlnst/2000-001-009.pdf 


\section{ANEXO I:}

Tabla 6. Ítems añadidos a la Escala de receptor/a/ perpetrador de la violencia.

\begin{tabular}{|c|c|}
\hline \multicolumn{2}{|r|}{ Escala de receptorla de la violencia a través del uso del VIH } \\
\hline $\begin{array}{c}\text { Item } \\
1\end{array}$ & 29. Mi pareja me ha amenazado con decir a otras personas que tengo $\mathrm{VIH}$ \\
\hline $\begin{array}{c}\text { Item } \\
2\end{array}$ & 30. Mi pareja me ha ocultado que tenía VIH y me ha contagiado \\
\hline $\begin{array}{c}\text { Item } \\
3\end{array}$ & 31. Mi pareja me ha impedido ir al doctor o a la clínica \\
\hline $\begin{array}{c}\text { Item } \\
4\end{array}$ & 32. Mi pareja me ha impedido tomar la medicación \\
\hline $\begin{array}{l}\text { Item } \\
5\end{array}$ & $\begin{array}{l}\text { 33. Mi pareja me ha dicho que si no estoy con él/ella al tener VIH otras personas no querrán } \\
\text { estar conmigo }\end{array}$ \\
\hline \multicolumn{2}{|r|}{ Escala de perpetrador/a de la violencia a través del uso del VIH } \\
\hline $\begin{array}{l}\text { Item } \\
1\end{array}$ & 13. He amenazado a mi pareja con decir a otras personas que tengo $\mathrm{VIH}$ \\
\hline $\begin{array}{c}\text { Item } \\
2\end{array}$ & 14. Oculté a mi pareja que tenía VIH y le contagié \\
\hline $\begin{array}{c}\text { Item } \\
3\end{array}$ & 15. He impedido a mi pareja ir al doctor o a la clínica \\
\hline $\begin{array}{c}\text { Item } \\
4\end{array}$ & 16. He impedido a mi pareja tomar la medicación \\
\hline $\begin{array}{c}\text { Item } \\
5\end{array}$ & $\begin{array}{l}\text { 17. Le he dicho a mi pareja que si no está conmigo al tener VIH otras personas no querrán } \\
\text { estar con él/ella }\end{array}$ \\
\hline
\end{tabular}

Nota: Valores de 1 a 5 considerando 1=nunca, 2=rara vez, $3=$ a veces, $4=$ frecuente y $5=$ muy frecuente. 


\section{ANEXO II:}

Tabla 7. Totales y frecuencias escalas de receptor/a de la violencia.

\begin{tabular}{|c|c|c|c|c|c|c|c|c|c|c|c|c|c|c|c|c|c|}
\hline \multirow{2}{*}{ Rece. } & \multirow{2}{*}{$\overline{\mathrm{x}}$} & \multirow{2}{*}{$\sigma$} & \multicolumn{2}{|c|}{ Si } & \multicolumn{2}{|c|}{ No } & \multirow{2}{*}{ Chi } & \multirow{2}{*}{ Sig } & \multirow{2}{*}{ Rece. } & \multirow{2}{*}{$\overline{\mathrm{x}}$} & \multirow{2}{*}{$\sigma$} & \multicolumn{2}{|c|}{ Si } & \multicolumn{2}{|c|}{ No } & \multirow{2}{*}{ Chi } & \multirow{2}{*}{ Sig } \\
\hline & & & $n$ & $\%$ & $n$ & $\%$ & & & & & & $n$ & $\%$ & $n$ & $\%$ & & \\
\hline V1 & 1.197 & .601 & 24 & 12.1 & 174 & 87.9 & 113.63 & .000 & V18 & 1.085 & .480 & 8 & 4 & 190 & 96.0 & 167.29 & 000 \\
\hline V2 & 1.191 & .655 & 22 & 11.1 & 176 & 88.9 & 119.77 & .000 & V19 & 1.070 & .433 & 8 & 4 & 190 & 96.0 & 167.29 & 000 \\
\hline V3 & 1.343 & .838 & 35 & 17.7 & 163 & 82.3 & 82.74 & .000 & V20 & 1.090 & .417 & 12 & 6.1 & 186 & 93.9 & 152.90 & 000 \\
\hline V4 & 1.176 & .624 & 20 & 11.1 & 178 & 88.9 & 126.08 & .000 & V21 & 1.080 & .381 & 11 & 5.6 & 187 & 94.4 & 156.44 & 000 \\
\hline V5 & 1.257 & .773 & 26 & 13.1 & 172 & 86.9 & 107.65 & .000 & V22 & 1.388 & .937 & 38 & 19.2 & 160 & 80.8 & 75.17 & 000 \\
\hline V6 & 1.459 & .964 & 48 & 24.2 & 150 & 75.8 & 52.54 & .000 & V23 & 1.065 & .403 & 7 & 3.7 & 191 & 96.3 & 170.99 & 000 \\
\hline V7 & 1.111 & .531 & 11 & 5.6 & 187 & 94.4 & 156.44 & .000 & V24 & 1.015 & .122 & 3 & 1.5 & 195 & 98.5 & 186.18 & 000 \\
\hline V8 & 1.378 & .902 & 38 & 19.2 & 160 & 80.8 & 75.17 & .000 & V25 & 1.146 & .465 & 23 & 11.6 & 175 & 88.4 & 116.68 & 000 \\
\hline V9 & 1.323 & .852 & 31 & 15.7 & 167 & 84.3 & 93.41 & .000 & V26 & 1.025 & .186 & 4 & 2 & 194 & 98.0 & 182.32 & 000 \\
\hline V10 & 1.096 & .445 & 11 & 5.6 & 187 & 94.4 & 156.44 & .000 & V27 & 1.050 & .241 & 9 & 4.5 & 189 & 95.5 & 163.63 & 000 \\
\hline V11 & 1.096 & .434 & 12 & 6.1 & 186 & 93.9 & 152.90 & .000 & V28 & 1.085 & .436 & 10 & 5.1 & 188 & 94.9 & 160.02 & 000 \\
\hline V12 & 1.232 & .702 & 27 & 13.6 & 171 & 86.4 & 104.72 & .000 & V29 & 1.055 & .429 & 4 & 2 & 194 & 98.0 & 182.32 & 000 \\
\hline V13 & 1.090 & .379 & 13 & 5.6 & 185 & 94.4 & 149.41 & .000 & V30 & 1.060 & .423 & 5 & 2.5 & 193 & 97.5 & 178.50 & 000 \\
\hline V14 & 1.050 & .373 & 5 & 2.5 & 193 & 97.5 & 178.50 & .000 & V31 & 1.000 & .000 & 0 & 0 & 198 & 100 & a & a \\
\hline V15 & 1.096 & .478 & 11 & 5.6 & 187 & 94.4 & 156.44 & .000 & V32 & 1.005 & .071 & 1 & 0.5 & 197 & 99.5 & 194.02 & 000 \\
\hline V16 & 1.065 & .350 & 10 & 5.1 & 188 & 94.9 & 160.02 & .000 & V33 & 1.045 & .406 & 3 & 1.5 & 195 & 98.5 & 186.18 & 000 \\
\hline V17 & 1.070 & .433 & 6 & 3 & 192 & 97.0 & 174.72 & .000 & & & & & & & & & \\
\hline
\end{tabular}

Nota: $\overline{\mathrm{x}}=$ media; $\sigma=$ desviación estándar; $C h i=$ chi cuadrado; Sig= significación bilateral; a= Esta variable es constante. No es posible realizar la prueba de chi-cuadrado. 
Tabla 8. Totales y frecuencias escalas de perpetradorla de la violencia.

\begin{tabular}{|c|c|c|c|c|c|c|c|c|}
\hline \multirow{2}{*}{ Perp. } & \multirow{2}{*}{$\overline{\mathrm{x}}$} & \multirow{2}{*}{$\sigma$} & \multicolumn{2}{|c|}{$S i$} & \multicolumn{2}{|c|}{ No } & \multirow{2}{*}{ Chi } & \multirow{2}{*}{ Sig } \\
\hline & & & $n$ & $\%$ & $n$ & $\%$ & & \\
\hline A1 & 1.156 & .533 & 18 & 9.1 & 180 & 90.9 & 132.54 & 000 \\
\hline $\mathrm{A} 2$ & 1.474 & .822 & 62 & 31.3 & 136 & 68.7 & 27.65 & 000 \\
\hline A3 & 1.545 & .898 & 68 & 34.3 & 130 & 65.7 & 19.41 & 000 \\
\hline A4 & 1.242 & .614 & 34 & 17.2 & 164 & 82.8 & 85.35 & 000 \\
\hline A5 & 1.232 & .634 & 28 & 14.1 & 170 & 85.9 & 101.83 & 000 \\
\hline A6 & 1.050 & .330 & 7 & 3.5 & 191 & 96.5 & 170.99 & 000 \\
\hline A7 & 1.277 & .759 & 31 & 15.7 & 167 & 84.3 & 93.41 & 000 \\
\hline A8 & 1.131 & .506 & 18 & 9.1 & 180 & 90.9 & 132.54 & 000 \\
\hline A9 & 1.065 & .364 & 9 & 4.5 & 189 & 95.5 & 163.63 & 000 \\
\hline A10 & 1.075 & .402 & 9 & 4.5 & 189 & 95.5 & 163.63 & 000 \\
\hline A11 & 1.090 & .405 & 13 & 6.6 & 185 & 93.4 & 149.41 & 000 \\
\hline A12 & 1.045 & .353 & 4 & 2 & 194 & 98.0 & 182.32 & 000 \\
\hline A13 & 1.025 & .292 & 2 & 1 & 196 & 99.0 & 190.08 & 000 \\
\hline A14 & 1.020 & .284 & 1 & 0.5 & 197 & 99.5 & 194.02 & 000 \\
\hline A15 & 1.020 & .284 & 1 & 0.5 & 197 & 99.5 & 194.02 & 000 \\
\hline A16 & 1.000 & .000 & 0 & 0 & 198 & 100 & $a$ & a \\
\hline A17 & 1.005 & .071 & 1 & 0.5 & 197 & 99.5 & 194.02 & 000 \\
\hline
\end{tabular}

Nota: $\overline{\mathrm{x}}=$ media; $\sigma=$ desviación estándar; $C h i=$ chi cuadrado; Sig= significación bilateral; a= Esta variable es constante. No es posible realizar la prueba de chi-cuadrado. 
